\title{
Injeção de gordura na prega vocal: efeitos do local de injeção sobre a configuração glótica e a distribuição espacial da gordura injetada
}

\author{
Rui Imamura', Luiz Ubirajara Sennes ${ }^{2}$, \\ Daniel Chung 3 , Saramira Bohadana ${ }^{4}$, \\ Domingos Hiroshi Tsuji ${ }^{5}$
}

\section{Fat injection into the vocal fold: effects of the place of injection on the configuration of the glottis and the spatial distribution of the fat}

\author{
Palavras-chave: paralisia das cordas vocais/terapia, \\ laringe/cirurgia, distúrbios da voz. \\ Key words: vocal cord paralysis/therapy, \\ larynx/surgery, voice disorders.
}

\section{Resumo / Summary}

\begin{abstract}
A injeção intracordal de gordura tem sido utilizada para medializar a prega vocal em casos de paralisia laríngea, com resultados variáveis. A ausência de consenso entre os autores em relação a diversos aspectos técnicos, como o local de injeção, pode contribuir, em parte, para essa variação. Objetivo: Estudar 0 efeito do local de injeção em relação à distribuição espacial da gordura dentro da prega vocal e à configuração glótica após essas injeções. Formadeestudo: Experimental. Material eMétodo: Seis laringes adultas excisadas foram utilizadas. Gordura colhida por lipoaspiração foi injetada, por meio de uma seringa de pressão, no ponto médio da prega vocal em três laringes e lateralmente ao processo vocal da aritenóide em outras três. Fotografias digitais em vista cranial da glote foram obtidas antes e após as injeções. Após fixação e descalcificação, as laringes foram cortadas no plano frontal nos terços anterior, médio e posterior da prega vocal e no nível da cartilagem aritenóide, para estudar a distribuição da gordura. Resultados Somente a injeção de gordura lateralmente ao processo vocal da aritenóide permitiu o fechamento da glote posterior. A gordura tendeu a ocupar um espaço cilíndrico dentro do músculo tireoaritenóideo, ao longo do maior eixo da prega vocal, mesmo quando injetada próximo ao processo vocal. Conclusões 0 local de injeção da gordura teve influência sobre a configuração glótica após a injeção, apesar da gordura tender a ocupar um espaço cilíndrico ao longo da prega vocal em ambos os grupos.
\end{abstract}

ntracordal fat injection has been used for vocal fold medialization in cases of laryngeal paralysis with variable results. A lack of consensus among the authors concerning various technical aspects, such as the site of injection, may contribute, in part, to this variation. Aim: To study the effects of the place of fat injection on the spatial distribution of fat and the configuration of the glottis after the injections. Study design: Experimental. Material and Method: Six adult excised larynges were used. Fat harvested by liposuction was injected with a high-pressure syringe in the middle point of the vocal fold in three larynges and lateral to the vocal process of the arytenoid in another three. Digital photographs from a cranial view of the glottis were obtained before and after the injections. After fixation and decalcification, the larynges were cut in the frontal plane at the anterior, middle and posterior thirds of the vocal fold and at the level of the arytenoid cartilage in order to study the distribution of fat. Results: Closure of the posterior glottis was observed only when fat was injected lateral to the vocal process of the arytenoid. Fat tended to occupy a cylindrical space inside the thyroarytenoid muscle, along the longer axis of the vocal fold, even when injected close to the vocal process of the arytenoid. Conclusion: The place of fat injection influenced the configuration of the glottis after injection, although the fat tended to occupy a cylindrical space along the longer axis of the vocal fold in both groups.

\footnotetext{
${ }^{1}$ Médico assistente doutor da Divisão de Clínica Otorrinolaringológica do Hospital das Clínicas da Faculdade de Medicina da Universidade de São Paulo.

2 Professor livre-docente da Disciplina de O torrinolaringologia da Faculdade de Medicina da Universidade de São Paulo.

${ }^{3}$ Doutorando da Disciplina de O torrinolaringologia da Faculdade de Medicina da Universidade de São Paulo.

${ }^{4}$ Médica otorrinolaringologista doutora pela Faculdade de Medicina da Universidade de São Paulo.

${ }^{5}$ Professor livre-docente da Disciplina de Otorrinolaringologia da Faculdade de Medicina da Universidade de São Paulo.

Trabalho realizado na Divisão de Clínica Otorrinolaringológica do Hospital das Clínicas da Faculdade de Medicina da Universidade de São Paulo - Serviço do Prof. Dr. Aroldo Miniti.

Endereço para Correspondência: Dr. Rui Imamura - Av. Liberdade, 91 conj. 91/3 São Paulo SP 01503-000 Brasil

Trabalho apresentado no $36^{\circ}$ Congresso Brasileiro de Otorrinolaringologia, realizado de 18 a 23 de Novembro de 2002, em Florianópolis - SC. Artigo recebido em 30 de maio de 2003. Artigo aceito em 17 de julho de 2003.
} 


\section{INTRODUÇÃO}

Diversos materiais injetáveis, como teflon, colágeno, silicone e gelfoam ${ }^{1-3}$ têm sido utilizados para medializar a prega vocal em casos de paralisia laríngea com comprometimento do fechamento glótico. Mais recentemente, a gordura tem sido apontada como uma boa alternativa, já que apresenta diversas qualidades: é autóloga e fácil de colher por lipoaspiração, apresenta risco mínimo de formação de granuloma e de reação de corpo estranho ou hipersensibilidade ${ }^{4,5}$.

Contudo, a utilização de gordura para injeção intracordal também apresenta limitações. A principal delas é a incapacidade de se prever com precisão o resultado final da medialização, uma vez que a gordura pode ser reabsorvida em porcentagens variáveis (em geral, cerca de $50 \%)^{6}$. Dessa forma, preconiza-se que uma quantidade extra de gordura ( 30 a $50 \%$ ) seja injetada para compensar perdas futuras com a reabsorção $0^{4,5,7}$.

O utro fator que dificulta uma estimativa do resultado final é o desconhecimento sobre o espaço que a gordura injetada ocupa dentro da prega vocal e qual o efeito de sua presença sobre a configuração glótica, sobre o contorno da borda livre e sobre as propriedades viscoelásticas de cada camada da prega vocal.

De modo geral, acredita-se que injeções profundas, dentro do músculo tireoaritenóideo (TA), permitam a medialização adequada da prega vocal com pouca interferência sobre as propriedades viscoelásticas das camadas mais superficiais e, portanto, sobre o fenômeno vibratório. Contudo, não existe padronização do local de injeção na prega vocal: se ela deve ser realizada em um ou mais pontos, dentro do músculo TA ou do espaço paraglótico e qual a profundidade de injeção mais adequada. Mikaelian et al. (1992) ${ }^{7}$ e Shaw et al. (1997) ${ }^{4}$ sugerem que a injeção deva ser feita dentro do músculo TA em dois ou três pontos. Mikus et al. (1995) ${ }^{8}$ realizam a injeção apenas no terço médio da prega vocal, a uma profundidade de $2 \mathrm{~mm}$. Já Brandenburg et al. (1996) ${ }^{5}$ preferem a injeção imediatamente anterior e posterior ao terço médio da prega vocal. Shindo et al. (1996) ${ }^{9}$ realizam a injeção em dois pontos: no terço médio da prega vocal e lateralmente ao processo vocal da aritenóide. A maioria destes autores não especifica a profundidade e a distância em relação à borda livre com que fazem a injeção, apenas referindo que ela deve ser realizada dentro do músculo TA.

Em relação à configuração glótica, a literatura mostra que a medialização promovida pela injeção intracordal de gordura limita-se às porções anteriores da prega vocal e não permite corrigir fendas posteriores ${ }^{10}$.

0 objetivo deste estudo foi o de avaliar o efeito da gordura injetada dentro do músculo TA no ponto médio da prega vocal e lateralmente ao processo vocal da aritenóide em relação à distribuição espacial da gordura e à configuração glótica, após essas injeções.

\section{MATERIAL E MÉTODO}

0 estudo foi realizado com seis laringes humanas adultas excisadas de cadáveres, obtidas do Serviço de Verificação de Ó bitos da Capital da Faculdade de Medicina da USP. Q uatro laringes eram masculinas e duas, femininas. A média de idade dos cadáveres doadores foi de 45,33 anos (25 a 60 anos).

As laringes foram removidas num intervalo menor que 24 horas após o óbito. A gordura para injeção intra-cordal foi obtida, na mesma ocasião, por lipoaspiração da região abdominal de um dos cadáveres, segundo técnica descrita por Brandenburg et al. (1992). Nenhuma laringe mostrava alterações morfológicas de suas estruturas e as pregas vocais e aritenóides eram móveis simetricamente.

As estruturas supraglóticas foram removidas para exposição adequada da glote e as laringes foram fixas em suporte próprio. A linha média da glote foi delimitada através de uma agulha ou fio de Nylon 2-0 passados desde a comissura anterior até o ponto médio da lâmina da cartilagem cricóidea.

A gordura colhida por lipoaspiração foi decantada em gaze para remover seu componente seroso, e então, introduzida numa seringa de pressão própria para injeção de gordura. Essa seringa foi acoplada a um Gelco de calibre 18.

Em três laringes, a injeção foi realizada no ponto médio da prega vocal, em sua superfície vestibular, com 0 intuito de atingir o músculo TA. Introduziu-se a agulha cerca de 3 a $4 \mathrm{~mm}$ lateralmente a sua borda livre, ap rofundando-a cerca de 2 a $4 \mathrm{~mm}$. Nas demais laringes a injeção foi realizada posteriormente, num ponto lateral ao processo vocal da aritenóide, na mesma profundidade. 0 bisel da agulha foi direcionado lateralmente em todas as injeções. Em cada laringe, injetou-se gordura lentamente em quantidade suficiente para que a borda livre da prega vocal atingisse a linha média da glote. A injeção foi realizada em uma única prega, mantendo-se a contralateral como controle.

Fotografias em vista cranial da glote foram obtidas antes e após as injeções por meio de uma câmera digital (Sony Mavica), sustentada por um tripé.

Em seguida, as laringes foram fixadas em formol a $10 \%$ por 10 dias e posteriormente descalcificadas em ácido nítrico a 7\% por mais 3 dias. Elas foram, então, cortadas no plano frontal na porção anterior, média e posterior da prega vocal e ao nível da cartilagem aritenóide. Os cortes foram realizados manualmente, utilizando-se uma lâmina de micrótomo descartável.

As superfícies cortadas foram dispostas ao lado de uma escala milimetrada e fotografadas com a mesma câmera digital. As imagens digitalizadas foram, então, processadas no programa Corel PhotoPaint v.10, para se ilustrar as regiões ocupadas pelo bolo de gordura (demonstrado em amarelo), músculo TA (em vermelho) e a superfície interna da cartilagem tireóidea (em azul). 


\section{RESULTADOS}

\section{Configuração glótica}

A borda livre da prega vocal tendeu a ficar abaulada (com uma convexidade), quando a gordura foi injetada no terço médio da prega (Figura 1c). Em nenhum desses casos houve adução do processo vocal da aritenóide e fechamento da porção cartilaginosa da glote (Figura 1). Esse fato foi, contudo, observado quando a gordura foi injetada lateralmente ao processo vocal da aritenóide (Figura 2). Por outro lado, injeções nesse ponto nem sempre permitiram um fechamento adequado de porções anteriores da glote (Figura 2a). A análise dos cortes frontais da laringe mostrou que, nos casos em que houve medialização do processo vocal, a gordura ocupou a região lateral ao corpo da cartilagem aritenóide (Figura 3).

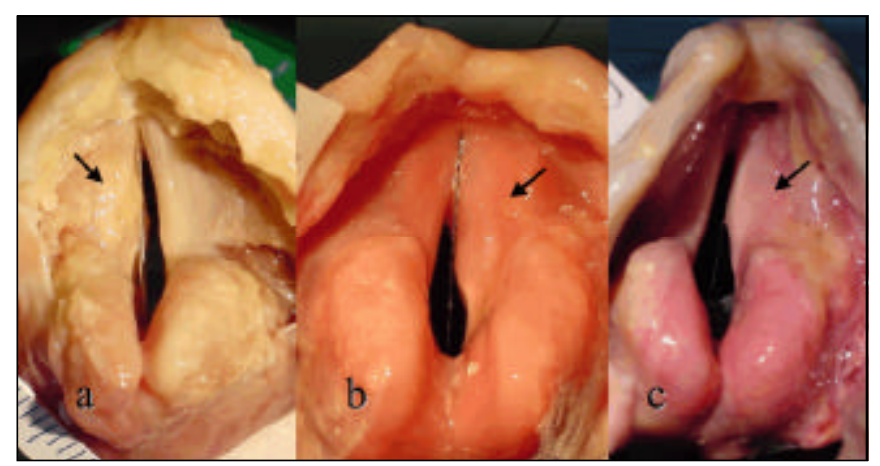

Figura 1. Configuração glótica após injeção intracordal de gordura no terço médio da prega vocal. As setas indicam o local de injeção. Observe que a glote posterior não se fecha em nenhum caso.

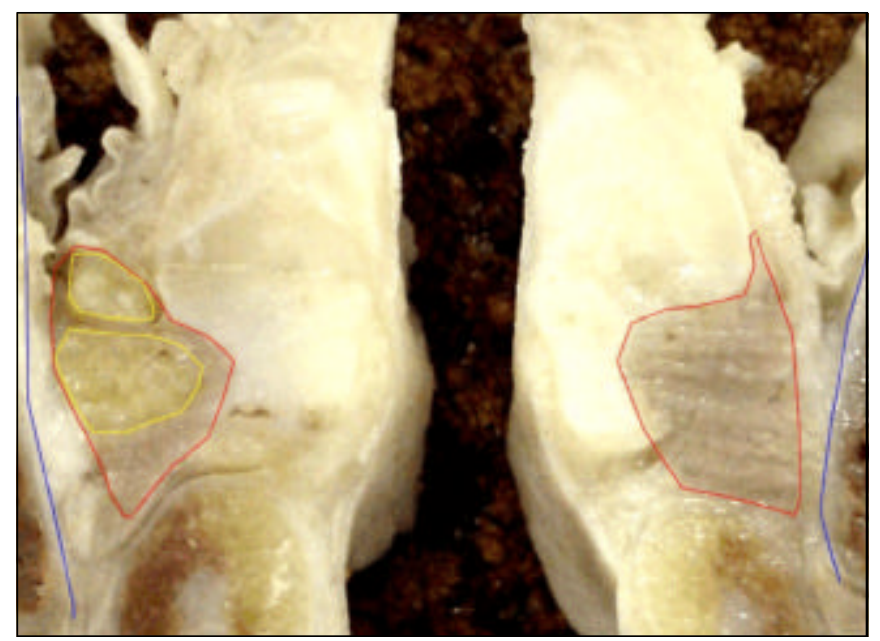

Figura 3. Corte frontal da laringe no nível da cartilagem aritenóide em um caso em que houve fechamento da glote posterior. Observe que a gordura posiciona-se lateralmente à cartilagem aritenóide, ocupando o espaço existente ente ela e a lâmina da cartilagem tireóide.

\section{Distribuição da gordura injetada}

O bservamos que o bolo de gordura injetado ocupou um espaço cilíndrico, ou ovóide, ao longo do maior eixo da prega vocal. Assim, nos cortes frontais seqüenciais, a gordura apareceu de forma circular ou ovalada, ocupando uma determinada área dentro do músculo TA, que tendeu a ser menor nas extremidades e maior no local em que foi feita a injeção (Figura 4). Em diversas laringes, a gordura injetada profundamente ao músculo TA difundiu-se, aproximandose das camadas mais superficiais da prega vocal (Figura 5). Em uma laringe, o bolo de gordura ocupou porções correspondentes à lâmina própria da prega vocal (Figura 5c). Em porções posteriores da prega vocal, a gordura tendeu a limitar-se ao músculo injetado (TA) e não a extravasar para outros músculos, como o cricoaritenóideo lateral (CAL) (Figura 6). Mesmo quando injetada na região lateral ao

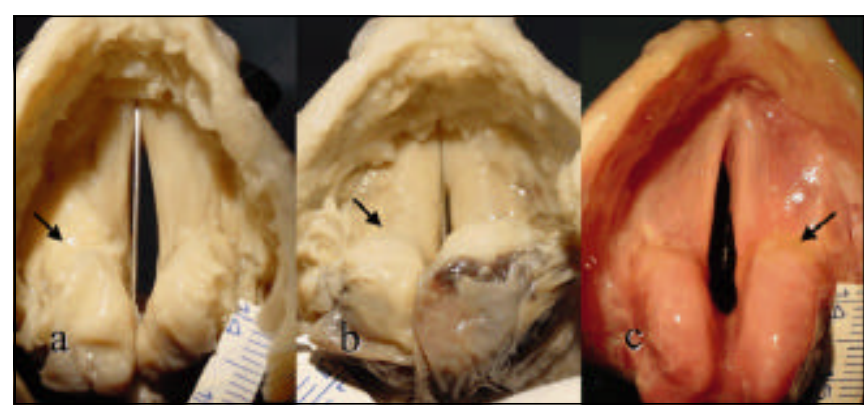

Figura 2. Configuração glótica após injeção intracordal de gordura lateralmente ao processo vocal da cartilagem aritenóide. As setas indicam o local de injeção. Existe uma tendência de fechamento da glote posterior e o perfil da glote assume um formato mais retilíneo.

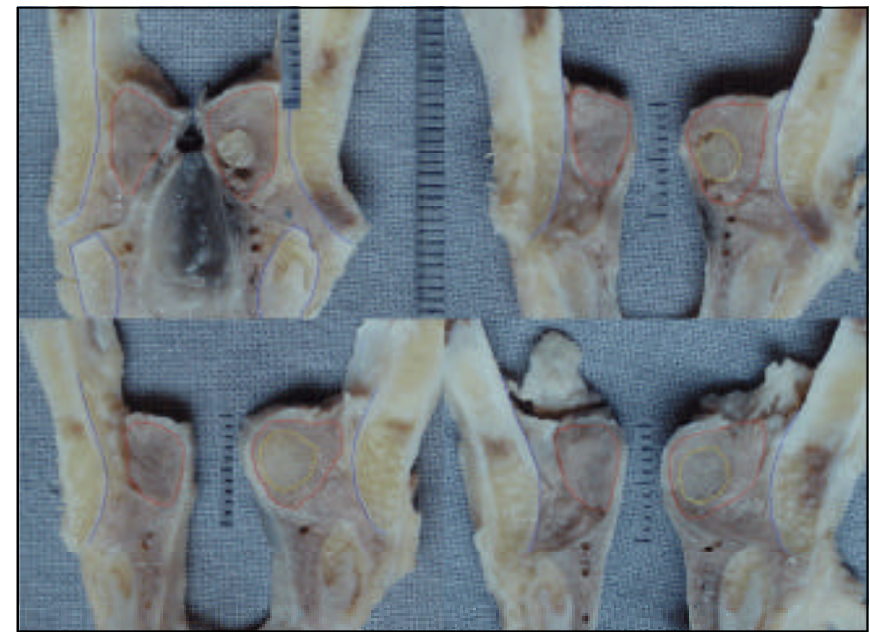

Figura 4. Cortes frontais de uma laringe após injeção de gordura no terço médio da prega vocal. 0 bolo de gordura assume um formato cilíndrico ao longo do maior eixo do músculo tireoaritenóideo. 
processo vocal da aritenóide, a gordura tendeu a distribuirse anteriormente, ocupando o espaço citado (Figura 7).

\section{Profundidade de injeção da prega vocal}

Em duas laringes em que injeções superficiais no músculo TA foram realizadas, a gordura permeou por entre as fibras do músculo atingindo sua periferia, promovendo abaulamentos da superfície vestibular da prega vocal (Figura 8). Além de não promover uma medialização adequada da prega, a deposição da gordura nessa região favoreceu a sua extrusão pelo orifício de punção (Figura 8a).

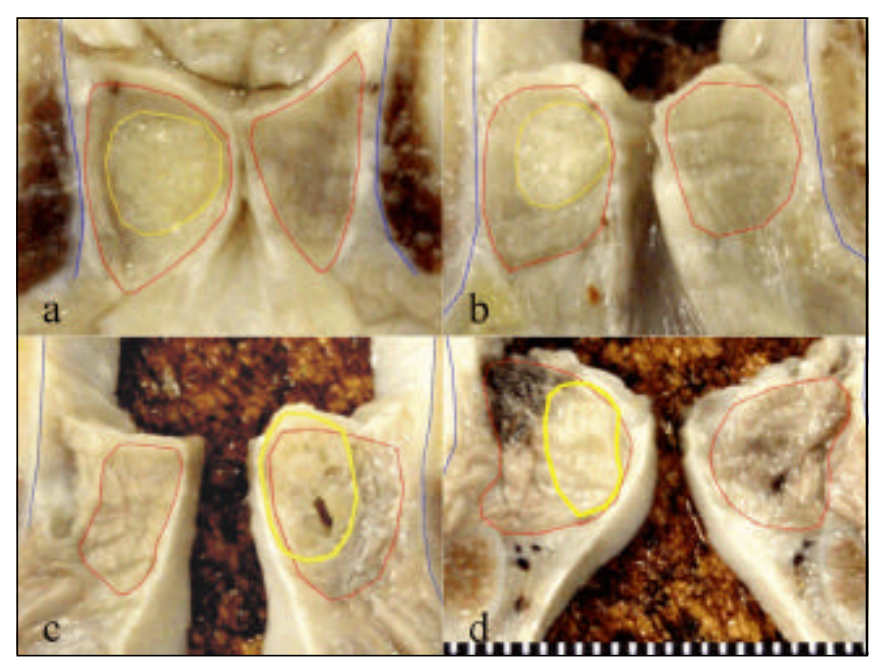

Figura 5. Injeção de gordura realizada profundamente no músculo tireoaritenóideo. Mesmo nessa situação, o bolo de gordura tendeu a se aproximar das camadas mais superficiais da prega vocal em diversas laringes. Ocasionalmente, chegou a ultrapassar os limites do músculo e atingir a lâmina própria da prega vocal (Figura $5 \mathrm{c}$ ).

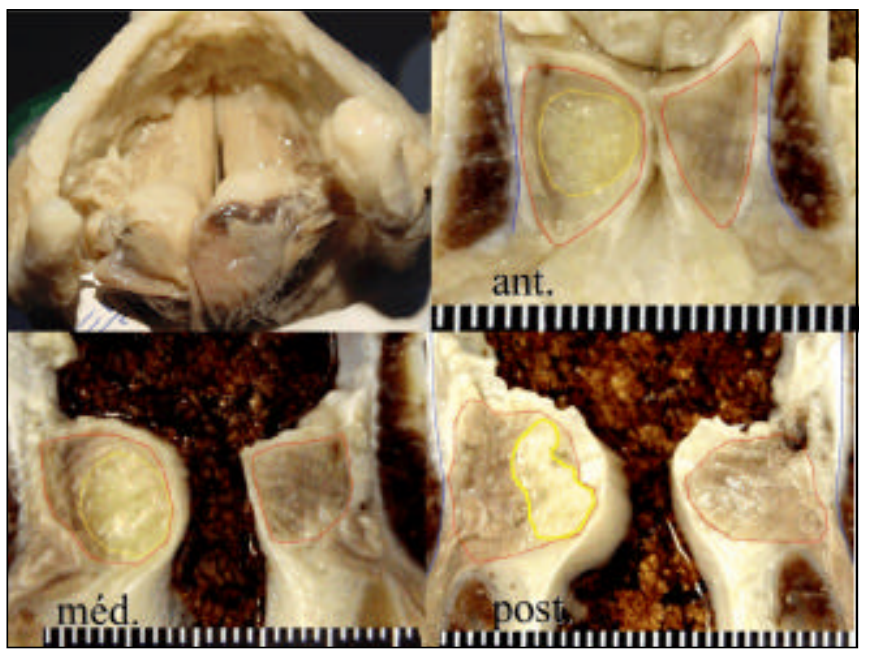

Figura 7. Configuração glótica e cortes frontais de uma laringe em que se realizou a injeção de gordura lateralmente ao processo vocal da aritenóide. Observe que o bolo de gordura atinge não só os terços posterior (post.) e médio (méd.), como também o terço anterior (ant.) da prega vocal.

\section{DISCUSSÃO}

Desde que a gordura foi proposta como material a ser utilizado para injeções intracordais ${ }^{11}$, muitos estudos têm abordado o problema da reabsorção da gordura no período pós-operatório e a conseqüente deterioração da qualidade vocal $^{4-6,8-12}$. A literatura, contudo, é pobre no que tange à distribuição espacial da gordura injetada e seus efeitos sobre o contorno da borda livre, configuração glótica e alterações das propriedades viscoelásticas de cada camada da prega vocal. Neste estudo, procuramos esclarecer algumas destas

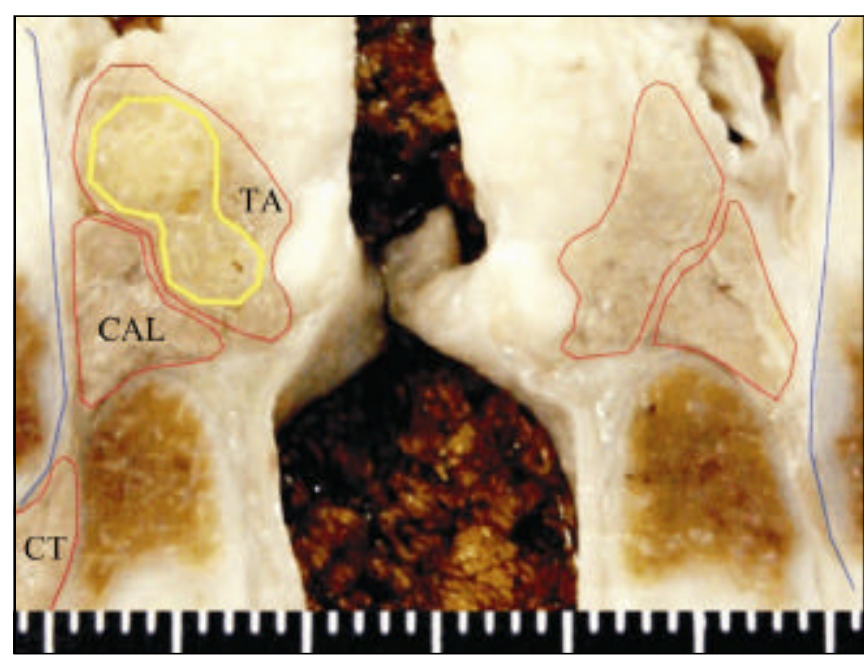

Figura 6. Corte frontal de uma laringe demonstrando a localização da gordura nas porções mais posteriores da prega vocal. A gordura permanece dentro do músculo tireoaritenóideo (TA), não se difundindo para os músculos cricoaritenóideo lateral (CAL) ou cricotireóideo (CT).

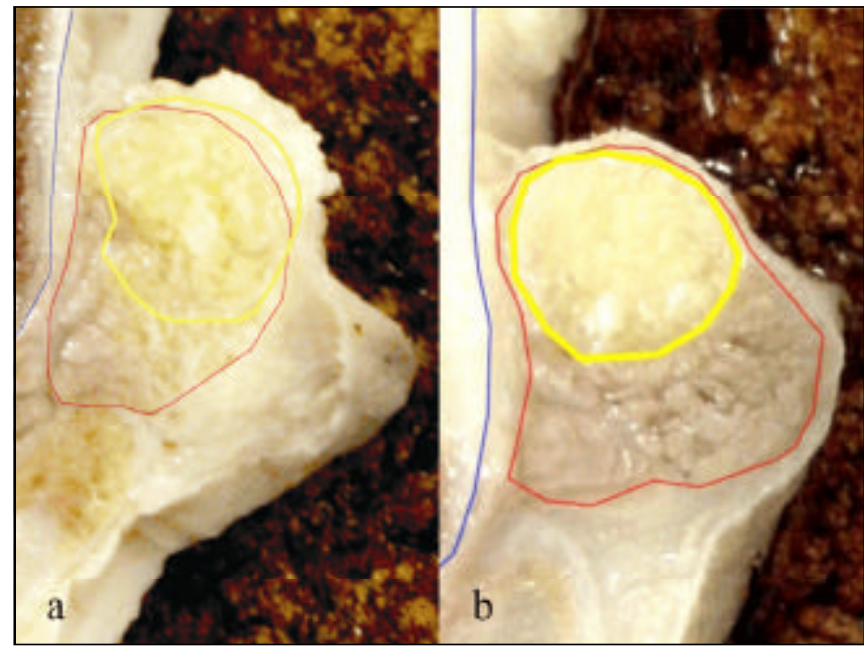

Figura 8. Cortes frontais de laringes demonstrando situações em que o bolo de gordura posicionou-se muito superficialmente, quando a injeção não foi realizada a uma profundidade adequada. Note 0 extravasamento da gordura na Figura $8 a$. 
questões. 0 número limitado de laringes utilizado e o caráter experimental do estudo sugerem que a transposição dos resultados para a prática clínica deve ser realizada com cautela. Pode-se inferir, contudo, sobre o que é possível de acontecer quando se injeta gordura nas pregas vocais. Acreditamos que este conhecimento possa fornecer fundamentos para futuros estudos clínicos.

Em relação à configuração glótica, observamos diferenças quando a injeção foi realizada no ponto médio da prega vocal ou lateralmente ao processo vocal da aritenóide. Em nenhuma laringe do primeiro grupo obteve-se medialização do processo vocal, com fechamento da glote posterior. Por outro lado, esse fato foi observado, em maior ou menor grau, em todas as laringes do segundo grupo. Dessa forma, consideramos que injeção de gordura pode promover o fechamento da glote posterior pela medialização do processo vocal da aritenóide, contrariamente ao referido na literatura ${ }^{10}$.

Nas laringes em que a gordura foi injetada no ponto médio da prega vocal, a medialização foi obtida às custas do abaulamento da porção membranosa da glote, com a formação de uma convexidade da borda livre. Na prática clínica, quanto mais lateralizada a prega vocal paralisada, maior a quantidade de gordura necessária para promover a sua medialização e, conseqüentemente, maior a convexidade da borda livre. Essa configuração não retilínea da borda livre da prega vocal, pode, contudo, prejudicar o fechamento adequado da glote. Estudando o uso da gordura para o tratamento de paralisia laríngea unilateral, Shaw et al. (1997) referem que a qualidade vocal de muitos de seus pacientes melhorou com o tempo, atribuindo esta melhora à reabsorção do excesso de gordura injetado e diminuição da convexidade da borda livre, com conseqüente melhora do fechamento glótico. Dessa forma, injeções somente da porção média da prega vocal, quando esta se encontra lateralizada, levam a um paradoxo: para se promover um bom fechamento glótico pode ser necessário que a borda livre fique um pouco convexa. Por outro lado, essa convexidade pode prejudicar o fechamento glótico.

Consideramos, portanto, que a injeção de gordura num ponto lateral ao processo vocal da aritenóide e, em menor quantidade, no terço médio da prega vocal, de modo semelhante ao realizado por Shindo et al. $(1996)^{9}$, pode resultar num fechamento completo da glote, sem que seja necessário provocar uma deformação acentuada da borda livre. Ao menos em situações experimentais, esta técnica parece apresentar vantagens em relação à injeção exclusiva do terço médio da prega vocal.

O bservamos também que a injeção de gordura num único ponto pode permitir o fechamento completo da glote pela tendência de distribuição da gordura num eixo ânteroposterior, dentro do músculo TA. Conforme ilustrado na Figura 7, a gordura, quando injetada lateralmente ao processo vocal, pode difundir-se até 0 terço anterior da glote, sem ultrapassar os limites do músculo TA, no plano frontal. 0 músculo TA, portanto, parece oferecer maior resistência à difusão da gordura no plano frontal que no eixo longitudinal da prega vocal. Este achado é teoricamente esperado já que as fibras deste músculo caminham em direção ântero-posterior, ao longo da prega vocal. Cada fibra muscular é presa às fibras adjacentes por um tecido conjuntivo de sustentação e um intrincado complexo de proteínas (complexo distrofina-glicoproteína), que as mantém unidas ${ }^{13}$. Por outro lado, os espaços existentes entre as fibras musculares, ocupados pelo endomísio, formam verdadeiros "corredores" que oferecem pouca resistência mecânica à difusão de substâncias. Dessa forma, a restrição imposta pelas fibras musculares à difusão da gordura é menor no sentido do maior eixo do músculo, que perpendicular a ele.

Essa tendência de difusão ântero-posterior, contudo, não promoveu a migração da gordura injetada no terço médio da prega vocal para a região lateral ao processo vocal da aritenóide. Como dito antes, nenhum caso em que a injeção foi realizada no terço médio da prega vocal cursou com medialização do processo vocal da aritenóide. Consideramos que nas extremidades do músculo TA, as fibras musculares encontram-se muito próximas umas das outras, diminuindo os espaços inter-fibras o que pode aumentar a resistência tecidual à difusão da gordura. A pesar da gordura injetada próximo à extremidade posterior do músculo TA poder se difundir para os terços médio e anterior da prega vocal, 0 inverso parece ser menos provável.

Segundo os achados deste estudo consideramos desnecessário realizar injeções em vários pontos da prega vocal conforme preconizado por alguns autores ${ }^{4,5,7,9}$. Uma vez que a gordura injetada pode extravasar pelo ponto de injeção ${ }^{8}$, quanto maior o número de injeções, maior o risco de estravasamento e pior o controle sobre o volume final de gordura.

Em relação à possibilidade de extravasamento, observamos que a gordura ocasionalmente atingiu a periferia do músculo TA e promoveu abaulamentos não desejados na superfície vestibular da prega vocal. Uma vez que a gordura alcança essa superfície, a probabilidade de extrusão é maior. Isto ocorre quando a injeção de gordura é muito superficial ou muito próximo à borda livre da prega vocal e o raio de difusão da gordura injetada ultrapassa os limites do músculo. Para se evitar esse tipo de situação, é necessário que o gordura seja injetada profundamente dentro do músculo TA.

Mesmo seguindo estes cuidados, em alguns casos, a gordura injetada difundiu-se consideravelmente, aproximando-se das camadas mais superficiais da prega vocal. Esses achados permitem tecer al gumas considerações teóricas em relação aos efeitos da gordura injetada sobre a organização estrutural em camadas da prega vocal e às propriedades viscoelásticas de cada camada. 
Na tireoplastia tipo I, a medialização da prega é obtida pela introdução de um bloco de silicone que empurra as estruturas paraglóticas em sentido medial. Nesse caso, a organização estrutural em camadas da prega vocal, é mantida, com uma diminuição progressiva da rigidez, à medida que se caminha no sentido das camadas mais superficiais. Segundo Hirano $(1975)^{14}$, a diferença das propriedades viscoelásticas de cada camada desempenha um papel importante nas características vibratórias da prega vocal. Tal fato é observado em casos de paralisia laríngea com atrofia intensa do músculo TA. Mesmo que haja fechamento completo da glote, não há formação adequada de ondas de vibração mucosa devido à perda de sustentação da mucosa promovida pelo músculo TA. Tanto a mucosa, como o músculo TA apresentam-se flácidos nesta situação. No caso da gordura, quando o bolo injetado aproxima-se das camadas superficiais da prega vocal, a diferença de rigidez em cada camada pode ficar reduzida, homogeneizando-as. A gordura, sendo um tecido macio e maleável, pode não fornecer a sustentação adequada à mucosa durante a vibração cordal. Dessa forma, é possível que as características vibratórias da prega abordada pela injeção de gordura sejam alteradas, com diminuição da formação de ondas mucosas, mesmo que haja um fechamento glótico completo. De fato, estudando pacientes com paralisia unilateral de prega vocal que se submeteram a injeção intracordal de gordura, Shaw et al. (1997) ${ }^{4}$ demostraram que apesar de significativa melhora do fechamento glótico, os pacientes não apresentaram melhora significativa quanto à formação de ondas mucosas após 1, 6 e 12 meses de pós-operatório. Contudo, análises perceptuais (GRBAS) e subjetivas realizadas pelos próprios pacientes deste estudo mostraram melhoras significativas da qualidade vocal no pós-operatório. 0 comprometimento do movimento mucoondulatório da mucosa nestes pacientes é uma limitação teórica cuja real relevância clínica precisa ser melhor estabelecida.

\section{CONCLUSÕES}

Este estudo permite concluir que, em condições experimentais:

- A injeção de gordura, quando realizada lateralmente ao processo vocal da aritenóide, permitiu o fechamento da glote posterior pela medialização do processo vocal da aritenóide. Quando realizada apenas no terço médio da prega vocal, promoveu um abaulamento da porção membranosa, sem fechamento da porção cartilaginosa da prega vocal.

- A gordura injetada dentro do músculo TA tende a ocupar um espaço cilíndrico ao longo do maior eixo da prega vocal, de modo que a injeção em um único ponto pode promover 0 abaulamento de toda a glote membranosa. Este fato pôde ser observado mesmo quando a gordura foi injetada lateralmente ao processo vocal da aritenóide.

\section{REFERÊNCIASBIBUOGRÁFICAS}

1. Schmidt PJ, Wagenfeld D, Bridger MW, van Nostrand AW, Briant TD. Teflon injection of the vocal cord: a clinical and histopathologic study. J Otolaryngol 1980; 9(4):297-302.

2. Stein J, Eliachar I, Myles J, Munoz-Ramirez H, Strome M. Histopathologic study of alternative substances for vocal fold medialization. Ann Otol Rhinol Laryngol 2000; 109(2):221-6.

3. Ford CN, Bless DM, Campbell D. Studies of injectable soluble collagen for vocal fold augmentation. Rev Laryngol Otol Rhinol (Bord) 1987; 108(1):33-6.

4. Shaw GY, Szewczyk MA, Searle J, Woodroof J. Autologous fat injection into the vocal folds: technical considerations and longterm follow-up. Laryngoscope 1997; 107(2):177-86.

5. Brandenburg JH, Unger JM, Koschkee D. Vocal cord injection with autogenous fat: a long-term magnetic resonance imaging evaluation. Laryngoscope 1996; 106(2):174-80.

6. Horl HW, Feller AM, Biemer E. Technique for liposuction fat reimplantation and long-term volume evaluation by magnetic resonance imaging. Ann Plast Surg 1991; 26:248-58.

7. Mikaelian DO, Lowry LD, Sataloff RT. Lipoinjection for unilateral vocal cord paralysis. Laryngoscope 1991; 101(5):465-8.

8. Mikus JL, Koufman JA, Kilpatrick SE. Fate of liposuctioned and purified autologous fat injections in the canine vocal fold. Laryngoscope 1995; 105(1):17-22.

9. Shindo ML, Zaretsky LS, Rice DH. Autologous fat injection for unilateral vocal fold paralysis. Ann Otol Rhinol Laryngol 1996; 105(8):602-06.

10. Chang HP, Chang SY. Autogenous fat intracordal injection as treatment for unilateral vocal palsy. Chung Hua I Hsueh Tsa Chih (Taipei) 1996; 58(2):114-20.

11. Brandenburg JH, Kirkham W, Koschkee D. Vocal cord augmentation with autogenous fat. Laryngoscope 1992; 102(5):495-500.

12. Kononas TC, Bucky LP, Hurley C, May Jr JW. The fate of suctioned and surgically removed fat after reimplantation for soft-tissue augmentation: A volumetric and histologic study in the rabbit. Plast Reconstr Surg 1993; 91(5):763-8.

13. Barohn RJ. In: Goldman L, Bennett, JC. Cecil - Textbook of Medicine, 21 $1^{\text {st. }}$ ed. Philadelphia: W.B. Saunders; 2000. p.2201-2.

14. Hirano, M. Phonosurgery. Basic and Clinical investigations. Otologia (Fukuoka) 1975; 21:239-440. 